\title{
DETERMINANTES DE LA INFORMALIDAD LABORAL EN COLOMBIA: UN ENFOQUE DESDE LA INMIGRACIÓN VENEZOLANA
}

Efrain Cuadro Guzman Universidad de Cartagena Colombia

Luis Daniel Trujillo Universidad de Cartagena Colombia

Carlos Lince Universidad de Cartagena Colombia 
Panorama Económico, Vol. 27 - No. 2 (Abril - Junio de 2019), pp. 387- 409

Efrain Cuadro Guzman

Luis Daniel Trujillo

Carlos Lince

JEL: J60, J61, J69

\title{
Determinantes de la informalidad laboral en Colombia: un enfoque desde la inmigración venezolana
}

\section{Resumen}

Este documento estudia la incidencia que ha tenido la inmigración venezolana en los últimos años con respecto a la informalidad vivida en Colombia para el periodo 2015-2018. Par ello se empleó un modelo logístico para determinar el grado de probabilidad que tiene un trabajador en Colombia de ser informal. Se utilizaron los microdatos de la Gran Encuesta Integrada de Hogares (GEIH) del Departamento Administrativo Nacional de Estadística (DANE), además de datos proporcionados por Migración Colombia, desagregados por las 23 principales ciudades del país. Los resultados indican que el ingreso de inmigrantes venezolanos, afecta los niveles de informalidad en el país, donde la probabilidad que un trabajador en Colombia sea informal aumenta en un $0,49 \%$ por cada 10.000 inmigrantes que habían ingresado a una determinada ciudad.

Palabras clave: Empleo informal, inmigración, mercado de trabajo, Venezuela.

\section{Déterminants de l'informalité du travail en colombie: une approche de l'immigration vénézuélienne}

\section{Résumé}

Ce document étudie l'incidence de l'immigration vénézuélienne ces dernières années en ce qui concerne l'informalité vécue en Colombie pour la période 2015-2018. Pour cela, un modèle logistique a déterminé le degré de probabilité qu'un travailleur en Colombie ait été informel. Les microdonnées de la grande enquête intégrée auprès des ménages (GEIH) du Département administratif national des statistiques (DANE) ont aidé en plus des données fournies par Migración Colombie, ventilées par les 23 principales villes du pays. Les résultats indiquent que le revenu des immigrants vénézuéliens affecte les niveaux d'informalité dans le pays, où la probabilité qu'un travailleur en Colombie soit informel augmente de 0,49\% pour 10000 immigrants qui sont entrés dans une certaine ville.

Palabras clave: Emploi informel, immigration, marché du travail, Venezuela.

\section{Determinants of labor informality in colombia: an approach from venezuelan immigration}

\begin{abstract}
This document studies the incidence that Venezuelan immigration has had in recent years with respect to the informality experienced in Colombia for the period 2015-2018. For this, a logistic model determined the degree of probability that a worker in Colombia has been informal. Micro data from the Large Integrated Household Survey (GEIH) of the National Administrative Department of Statistics (DANE) helped in addition to data provided by Migración Colombia, disaggregated by the 23 main cities of the country. The results indicate that the income of Venezuelan immigrants affects informality levels in the country, where the probability that a worker in Colombia is informal increases by $0.49 \%$ for every 10,000 immigrants who have entered a certain city.
\end{abstract}

Keywords: Informal employment, immigration, labor market, Venezuela. 


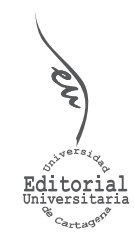

Artículo de Investigación

\section{Determinantes de la informalidad laboral en Colombia: un enfoque desde la inmigración venezolana'}

INFORMACIÓN DEL ARTíCULO

Recepción del artículo: 20/12/2018

Concepto de evaluación: 01/02/2019

Aceptación del artículo: 15/03/2019
Efrain Cuadro Guzman² Universidad de Cartagena, Colombia

Luis Daniel Trujillo Universidad de Cartagena, Colombia

Carlos Lince Universidad de Cartagena, Colombia

\section{INTRODUCCIÓN}

Los estudios sobre análisis de brecha salarial por género en Colombia y el mundo evidencian un fenómeno discriminatorio que no favorece a la mujer. Quiere decir esto, que aun en condiciones de mejor nivel educativo y experiencia se evidencian un diferencial en la asignación de los salarios el cual beneficia principalmente a los hombres. La importancia de conocer con claridad y certeza en donde subyacen los determinantes que potencializan la brecha salarial reside en poder generar política pública con la estructura y definición precisa que logre atenuar los procesos de índole discriminatoria que se producen en las dinámicas del mercado laboral. El trabajo infantil remunerado en sus distintos escenarios no es ajeno a esta realidad. Los datos expuestos a continuación dan cuenta de un número de niños y niñas en Colombia con diferenciales salariales algunas veces explicados por su nivel educativo y en otras quizá por la categoría de su género.

El presente artículo se ha diseñado en tres secciones, la primera se realiza un rastreo de información sobre estudios enfocados en el análisis de la brecha salarial. La segunda parte de Metodología y datos, que expone la situación de trabajo infantil - juvenil para el periodo de estudio 2012 - 2016 a partir de las estadísticas descriptivas en esta misma sección se desarrolla el modelo econométrico a partir de la utilización de la técnica

\footnotetext{
1. Agradecemos de manera muy especial a los economistas Rodrigo Salas y Jorge Luis Caro de la Universidad de Cartagena (Colombia), quienes contribuyeron significativamente, en el proceso de recolección, depuración y análisis de la información pertinente al logro de los objetivos de la investigación.

2. Autor de correspondencia: ecuadrog@unicartagena.edu.co
} 
Oaxaca - Blinder para analizar la existencia o no de diferencial salarial en el ejercicio remunerado de los niños y niñas entre 5 a 17 años en Colombia a partir de la información suministrada por la Gran Encuesta Integrado de Hogares y su módulo de trabajo infantil para los años 2012 a 2017.

\section{INTRODUCCIÓN}

Desde la antigüedad, los procesos migratorios han sido de mucho interés para las ciencias sociales, pues ellos comportan siempre tres grandes escenarios: uno, dejar atrás tragedias socioeconómicas o naturales; dos, buscar mejores expectativas de vida en otros lugares, o tres, ambas circunstancias simultáneamente, es decir, dejar atrás malas condiciones de vida y buscar mejorarla en el país de destino. Pero se acepta como regla general, que el desarraigo es doloroso y complejo en sus causas y secuelas, tanto para la región de origen, como para aquella de destino.

No obstante, lo malo que ello conlleva, entre los aspectos positivos que se pueden resaltar de un proceso migratorio, se destacan la llegada de inmigrantes muy preparados en diversas tecnologías y en ciencias que impulsen procesos de innovación. De igual forma la llegada de inmigrantes de bajo nivel de educación dispuestos a trabajar por un menor salario, lo cual es aprovechado por el empresariado residente, para bajar sus costos de producción. Otro aspecto es la posibilidad de los nacionales, de dejar ciertas labores tales como limpieza de ductos de aguas servidas, recolección de basura, limpieza en general, entre otros, a los inmigrantes que están dispuestos a trabajar por un sustento y poder enviar recursos a sus países de origen y así ayudar a sus familiares.

Durante el siglo XX se han presentado muchos procesos migratorios a nivel internacional generalmente hacia países desarrollados, con mejores condiciones de vida con mejores y mayores oportunidades de empleo e ingresos, principalmente. En efecto, Colombia registra una gran diáspora en todo el mundo, en gran parte también por los fenómenos de violencia, han impelido a miles de familias colombianas a emigrar hacia el extranjero.

Recientemente, en Colombia ha experimentado un proceso migratorio masivo, procedente de Venezuela. La oficina de Migración Colombia, con cifras a enero de 2019, estimó que la cantidad de venezolanos en Colombia correspondía a 1,2 millones (Becerra Elejalde, 2019). Situación que se ha dado a causa del contexto político y económico que está viviendo Venezuela y, por tanto, los migrantes están en búsqueda de mejores condiciones de vida. Para Aruj (2008) este proceso migratorio puede desencadenar en consecuencias negativas de tipo político, económico y social para Colombia. Se puede incrementar la competencia laboral, pueden surgir nuevos bolsones ${ }^{3}$ de pobreza, aumento de la discriminación, la xenofobia, entre otros. Puede ocurrir que los trabajadores menos calificados se perjudiquen por la pérdida de empleos - que irán a parar a los migrantes-o por la disminución de sus salarios.

En resumen, uno de los principales mercados que puede salir afectado es el mercado laboral y, por tanto, es importante revisar, las posibles consecuencias de los flujos migratorios, específicamente, en los índices de informalidad, en razón de que una llegada masiva de 
personas en edad de trabajar y en búsqueda de empleo, incrementando la oferta laboral teniendo en mente la limitada capacidad de absorción del tejido empresarial formal.

De esta manera, se busca analizar los efectos del reciente flujo migratorio de venezolanos hacia Colombia en los índices de informalidad laboral en los años 2015-2018. La siguiente sección presenta la literatura relevante sobre el tema de informalidad laboral, posteriormente se presentan el marco teórico y empírico, finalmente se presentan los resultados y las conclusiones.

\section{REVISIÓN DE LITERATURA}

La informalidad y los procesos migratorios, han sido temas de recurrente abordaje por diversos investigadores sociales y en todas las latitudes del mundo. Para este efecto, es ineludible consultar en primera instancia, a Gámez, Wilson, \& Boncheva (2010), quienes analizan las características del fenómeno migratorio en Baja California Sur, en la costa norte del Pacífico Mexicano, considerando a los sectores del turismo y la agricultura de exportación como atractores de población. Para los autores, esto ha estimulado una tasa de crecimiento demográfico promedio anual de $10 \%$ en la última década, de las que se alimentan los sectores formal e informal de la economía.

Por su parte, Valenzuela et al (2018) resaltan que en el actual contexto de la globalización, caracterizado por la reestructuración del sistema de producción capitalista y de las relaciones de trabajo, la migración presenta nuevas y particulares características. Precisan que, a nivel mundial, se está en presencia de una polarización del mercado laboral, donde conviven empleos estables y bien remunerados con otros informales y ocasionales. Sumado a ello, se encuentran con trabajadores informales en medios formales, lo cual evidencia las nuevas maneras en que se presenta la informalidad. En términos generales, clasifican a Chile como un país con una baja tasa de informalidad laboral; con una creciente llegada de inmigrantes laborales y una débil presencia del Estado en cuanto a la integración de la población extranjera. Observaron que la incorporación de éstos al mercado laboral nacional, considerados mano de obra barata, adquiere características particulares que a través de su investigación exploratoria con inmigrantes colombianos, haitianos y dominicanos (la "nueva inmigración") se buscó develar.

Importantes también son los aportes de Aguado Mazuera (2018) sobre la empleabilidad de los migrantes venezolanos en el mercado laboral de la ciudad de Cali (Colombia). Y en especial, consiguieron en su trabajo indagar sobre las percepciones de los migrantes venezolanos frente al mercado laboral en la ciudad de Santiago de Cali y analizar las competencias laborales de los migrantes venezolanos a la luz de los tres saberes (hacer, conocer y ser). En relación a los resultados, obtuvieron un 56\% para la categoría Macro Empleabilidad y un 44\% para la segunda categoría Macro Migración, concluyendo además que los migrantes que tienen doble nacionalidad, poseen una percepción más favorable respecto al mercado laboral de la ciudad.

Por otro lado, Contreras Guajardo et al. (2013) abordan los últimos procesos inmigratorios que ha experimentado Chile utilizando los datos de la encuesta CASEN de 2006 y 2009, además de los datos de Extranjería del Ministerio del Interior y del Ministerio de Relaciones Exteriores de ese país. Encontraron que, si bien existe un aumento de la inmigración al país, el número de inmigrantes en relación al porcentaje total de la población aún no es significativo. 


\section{MARCO TEÓRICO}

Al hablar de economía informal se observa que es un fenómeno que se consideraba un rasgo particular de algunas economías, especialmente de aquellas más atrasadas. Su implicación abre la discusión sobre la importancia que se debe prestar ante el aumento de su proporción en la actividad económica de todas las sociedades. David Ricardo menciona claramente la sustitutibilidad de mano de obra por máquinas y herramientas cuando afirma que "las proporciones en que el capital empleado para el sostenimiento del trabajo, y el invertido en herramientas, maquinaria y edificios, puede ser diversamente combinado" (Ricardo, 2003). Además, señala sobre los efectos de la mecanización de los procesos productivos cuando escribe que "la opinión mantenida por la clase trabajadora de que el empleo de la maquinaria es fundamentalmente perjudicial para sus intereses no está fundada en un prejuicio ni en un error, sino que se ajusta a los principios correctos de la economía política" (Ricardo, 2003, p. 332). Por otro lado, la tecnificación de los procesos productivos produce el desplazamiento sistemático del trabajo por la maquinaria (Marx, 1867).

La informalidad laboral se considera la consecuencia del escaso desarrollo en el sector moderno de la economía. En esta visión, los mercados laborales se encuentran segmentados por sus características estructurales, algunos con mejores tecnologías y más productivos, en contraste con sectores más atrasados y tradicionales con unas bajas productividades. El sector comprende un conjunto de actividades económicas, en las cuales existen economías a escala en capital físico y capital humano, traduciéndose en buenas condiciones laborales, oportunidades de crecimiento, estabilidad y adecuadas reglamentaciones laborales. Por otro lado, en los otros sectores menos desarrollados, se ofrecen empleos precarios con bajos salarios, escasas o bajas prestaciones laborales, alta inestabilidad, con una constante incertidumbre (Uribe, 2006).

Recientemente se plantea que las causas de la informalidad en una escogencia racional de los agentes: estos tienden a preferir ser informales para así no asumir los costos que les impone el Estado. Estos costos incluyen las obligaciones fiscales, parafiscales, sanitarias, laborales, entre otros, así como los costos relacionados con la legalización y el funcionamiento de la empresa. Por eso, según la visión institucional el culpable de la distorsión de la economía y la informalidad, es el Estado por todos aquellos costos transaccionales y por los gravámenes (Uribe, 2006).

\section{MARCO EMPÍRICO}

Se emplea el uso de un modelo logístico para determinar la incidencia que tienen las distintas variables independientes, en la probabilidad que tiene un trabajador para estar empleado en el mercado laboral informal. La población o universo de estudio de esta investigación está constituida por todas las personas ocupadas (formales e informales), encuestadas por el Departamento Administrativo Nacional de Estadística (DANE) en su Gran Encuesta Integrada de Hogares (GEIH); a su vez, se estudiaron las características de los migrantes procedentes de Venezuela en territorio colombiano, registrados por Migración Colombia. El periodo de análisis tuvo una periodicidad mensual y está comprendido desde enero de 2015 hasta diciembre de 2018. El modelo formalmente abordó las siguientes variables: 


\begin{tabular}{|c|c|c|}
\hline Variable & Indicador & Fuente \\
\hline \multicolumn{3}{|c|}{ Dependiente } \\
\hline Informalidad Laboral & Informalidad & GEIH - DANE \\
\hline \multicolumn{3}{|c|}{ Independientes } \\
\hline Sexo & Masculino $=1 ;$ Femenino $=0$ & \multirow{5}{*}{ GEIH - DANE } \\
\hline Rango de edad & $\begin{array}{l}\text { Menores de } 25 \text { años. } \\
\text { Entre } 25 \text { y } 40 \text { años. } \\
\text { Mayores de } 40 \text { años. }\end{array}$ & \\
\hline Jefe de hogar & $\begin{array}{l}\text { Jefe de hogar }=1 ; \\
\text { Dependiente }=0\end{array}$ & \\
\hline Migración Colombo-Venezolana & $\begin{array}{l}\text { Tasas de migración; } \\
\text { emigración y tasa neta. }\end{array}$ & \\
\hline Nivel de escolaridad & Número de años de estudio. & \\
\hline
\end{tabular}

Fuente: Elaboración propia

\section{RESULTADOS}

El comportamiento de las entradas de inmigrantes de Venezuela a Colombia y salidas de emigrantes de Colombia hacia Venezuela ha sido dinámico en los últimos años. Desde mediados de 2016 hasta mediados de 2018, la entrada de inmigrantes venezolanos ha tenido una tendencia en crecimiento, donde el mes de enero del 2018 fue el punto máximo alcanzado respecto a los años anteriores, con 135.042 inmigrantes. Por otro lado, las salidas de personas hacia Venezuela tienen un comportamiento más estable, no presentan unos cambios estructurales si se compara con las entradas de migrantes.

Gráfica 1: Entrada y salida de migrantes de Colombia a Venezuela

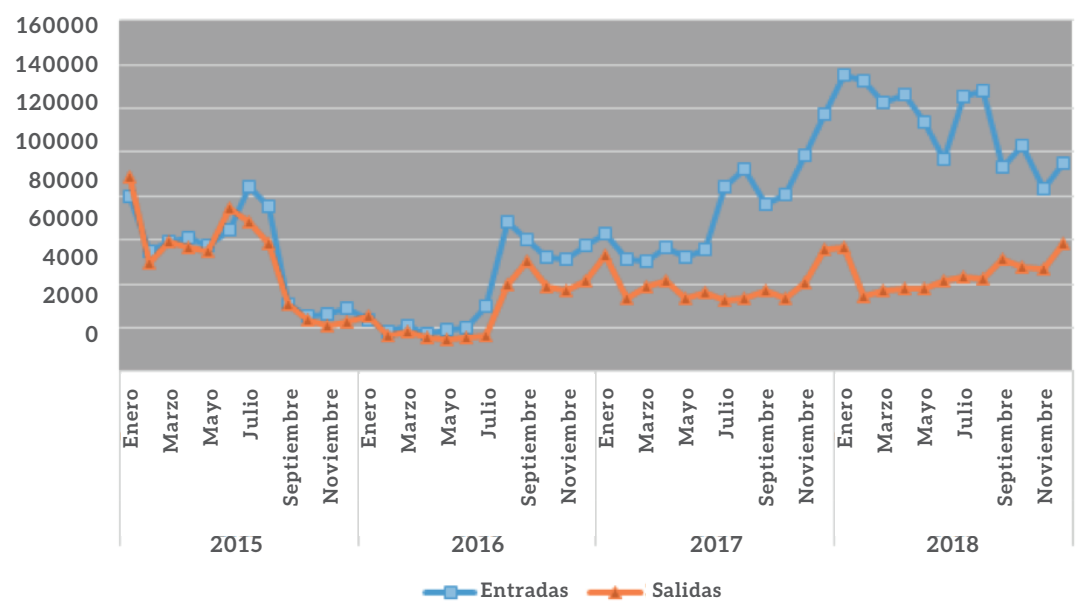

Fuente: Elaboración propia, con datos de Migración Colombia, 2019 
El anterior comportamiento podría apuntar a que en los años 2015 y 2016 la dinámica de la inmigración era que las personas que entraban a Colombia, lo hacían por motivos temporales (comercio, adquirir recursos que en su país no había, entre otros) y en poco tiempo regresaban a Venezuela. Por esta razón el 13 de agosto de 2016 Migración Colombia emite la tarjeta migratoria de tránsito fronterizo y recordó que la misma no es un documento de identificación, ni otorga derechos similares a aquellos a los que tendrían acceso los extranjeros que porten una visa o una cédula de extranjería. La tarjeta es un documento transitorio y que lo que se busca con la misma es facilitar la movilidad de los ciudadanos en zona de frontera, sin descuidar la seguridad (Migración Colombia, 2016).

Pero el proceso de los años 2017 y 2018, indica que los inmigrantes venezolanos tienen características permanentes. Por ello, el 28 de Julio de 2017 se creó el permiso especial de permanencia, el cual buscó regularizar la situación migratoria de más de 150 mil ciudadanos venezolanos. Este Permiso Especial habilita opciones de trabajar, estudiar y desarrollar cualquier tipo de actividad legal dentro del territorio nacional, siempre que el extranjero cumpliera con los demás requisitos establecidos en el ordenamiento jurídico colombiano. El permiso fue prorrogable por 90 días y se puede seguir prolongando hasta un máximo de 2 años.

\section{Gráfica 2: Flujo neto de inmigrantes de Venezuela}

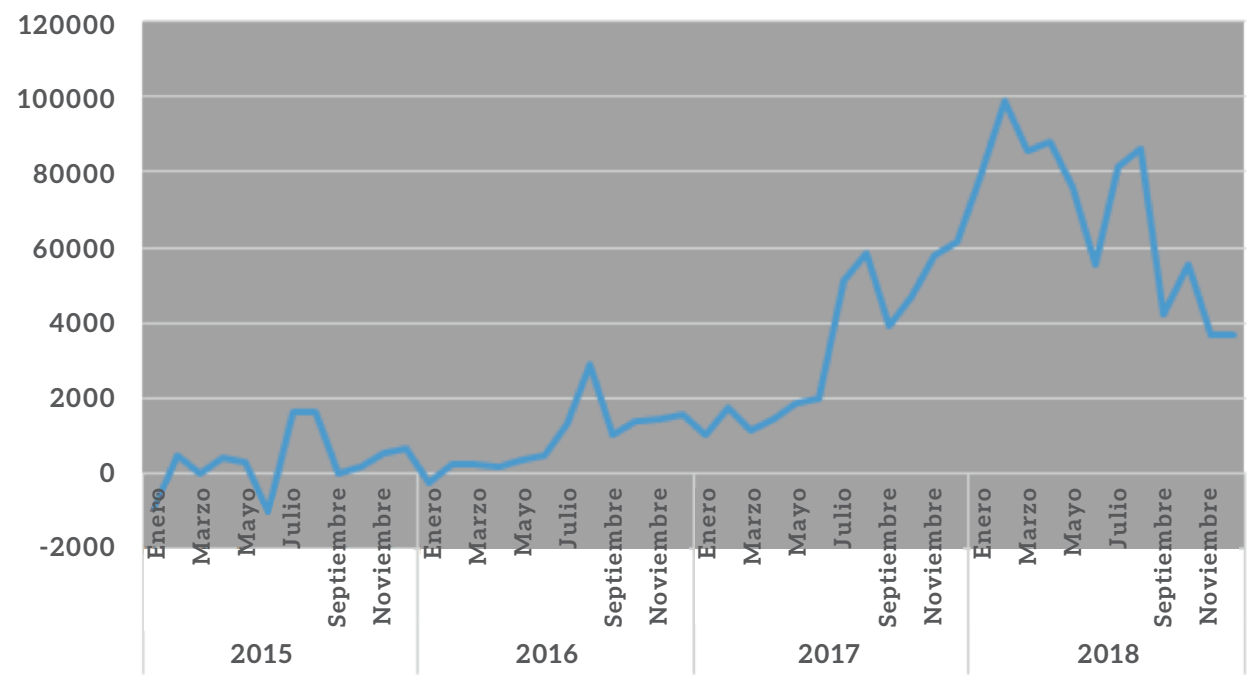

Fuente: Elaboración propia, con datos de Migración Colombia, 2019

Si se analiza el flujo neto de migrantes venezolanos, que es la diferencia entre los que entran frente a los que salen de Colombia, se observa que a partir de marzo del 2016 ha habido un progresivo crecimiento de migrantes en cuanto a los años anteriores. El mayor flujo que se observa se da entre enero y marzo del año 2018, pero el periodo donde el flujo alcanzó sus puntos más bajos, donde inclusive este fue negativo, fue entre enero y junio del 2015. Ya en agosto de 2015 la situación fue tornándose tensa debido a que el 19 de agosto de 2015 Venezuela de manera unilateral cierra la frontera 
del estado Táchira, limítrofe con el Departamento de Norte de Santander. Lo anterior se debe a un atentado que sufrieron militares venezolanos que dejaron 3 militares y un civil fallecidos, y que el Gobierno Venezolano atribuyó estos hechos a mafias del contrabando y grupos paramilitares colombianos que presuntamente tenían intereses económicos en la zona. El cierre de la frontera se estableció por 72 horas, mientras se hacían las investigaciones para dar con el paradero de los autores materiales del hecho (Migración Colombia, 2018).

Al finalizar los 3 días del hecho, el 22 de agosto de 2015, día en el cual se debía reabrir la frontera con el estado Táchira, la guardia venezolana irrumpió en barrios limítrofes con la frontera hacia Cúcuta en busca de colombianos en situación de ilegalidad; al encontrarlos, estos eran deportados y se procedía a la demolición de sus viviendas por parte de la guardia venezolana. Estos hechos dejaron como resultado 1.096 colombianos deportados, llevando al hombro estos seres humanos de nacionalidad colombiana, solo las pertenencias que podían cargar. En 25 de agosto de 2015 se aprobó el estado de excepción amparado en la Constitución Política de la República Bolivariana de Venezuela:

El presidente de la república, en Consejo de Ministros, podrá decretar los estados de excepción. Se califican expresamente como tales las circunstancias de orden social, económico, político, natural o ecológico, que afecten gravemente la seguridad de la Nación, de las instituciones y de los ciudadanos y ciudadanas, a cuyo respecto resultan insuficientes las facultades de las cuales se disponen para hacer frente a tales hechos. En tal caso, podrán ser restringidas temporalmente las garantías consagradas en esta Constitución, salvo las referidas a los derechos a la vida, prohibición de incomunicación o tortura, el derecho al debido proceso, el derecho a la información y los demás derechos humanos intangibles. (Art 337)

La Oficina de Naciones Unidas para la Coordinación de Asuntos Humanitarios (OCHA) contabilizaba 1.950 colombianos deportados por las fronteras de Norte de Santander, la Guajira y Arauca. Por el temor a ser deportados y por la difícil situación que ya se vivía en Venezuela, colombianos residentes en Venezuela deciden retornar a Colombia de manera voluntaria teniendo como resultado 22.342 colombianos retornados de manera voluntaria y registrados por las fronteras de Norte de Santander, la Guajira y Arauca (OCHA, 2019).

Gráfica 3: Entrada y salida de migrantes de Colombia a Venezuela, desagregado por género

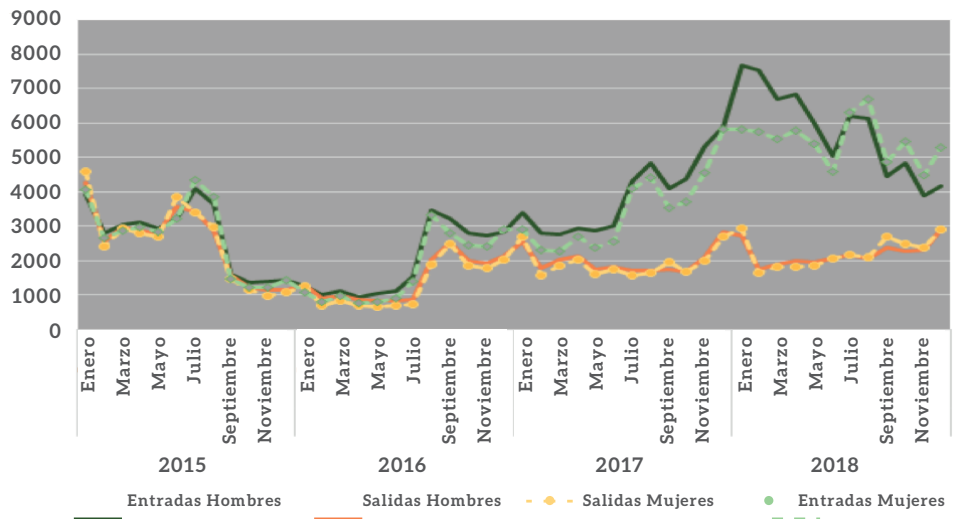

Fuente: Elaboración propia, con datos de Migración Colombia, 2019 
En cuanto a la inmigración venezolana por género, no se presenta una diferencia significativa entre hombres y mujeres. Referente a las entradas, se ven picos de inmigrantes hombres desde diciembre de 2017 hasta marzo de 2018; así mismo, hay picos de entrada de mujeres que van desde julio de 2018 hasta diciembre de 2018. El comportamiento anterior, podría estar relacionado con la apertura de la frontera por parte del Gobierno de Venezuela en el periodo de diciembre de 2017 y en junio de 2018. Además, esto también podría estar relacionado con un comportamiento sociológico donde el jefe de hogar, ingresa o migra primero al país para luego secundarle su pareja y/o familia.

La situación político electoral, junto a la inestabilidad económica creada por incremento en la emisión monetaria a finales de 2016, complementada por un sexto incremento del salario mínimo, con graves consecuencias inflacionarias, crearon un escenario de incertidumbre y desesperanza en la sociedad, favoreciendo la migración hacia varios países latinoamericanos, entre ellos Colombia (Scharfenberg, 2016; Gaceta oficial, 2017; Moreno Losada, 2017)

Mapa 1: Tasa de inmigrantes de Venezuela, desagregado por departamento

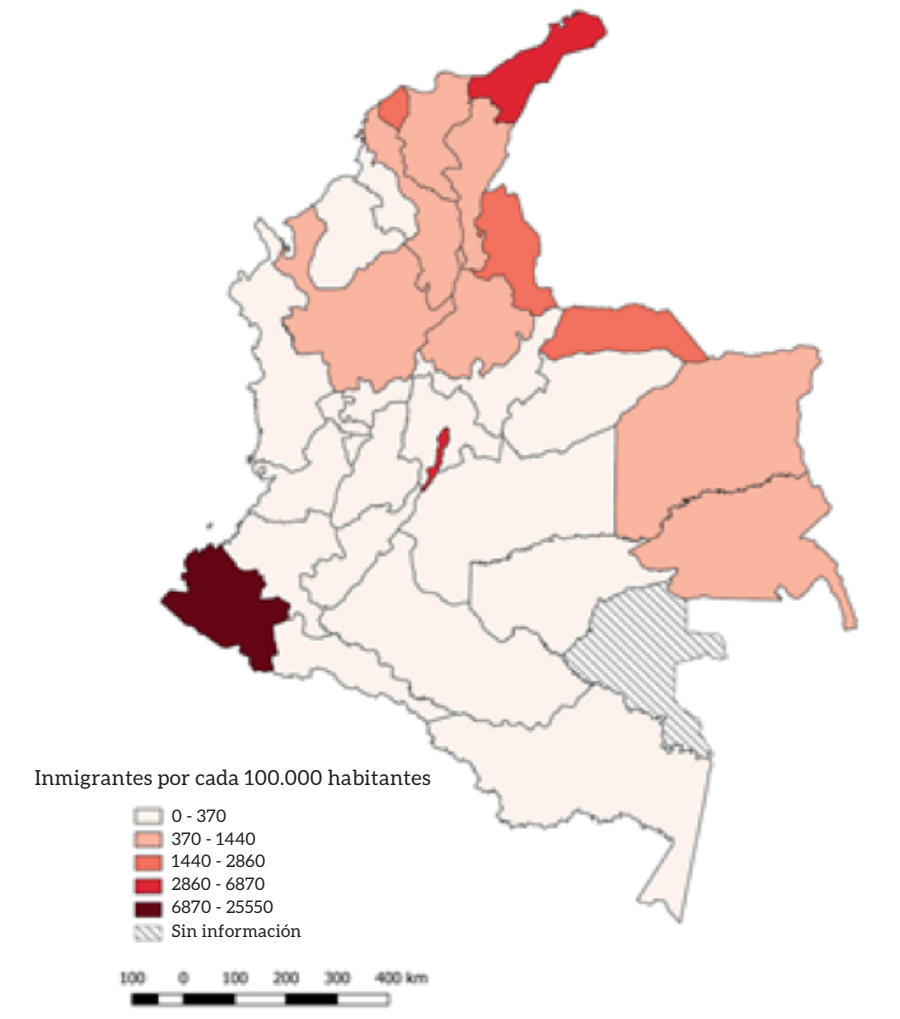

Fuente: Elaboración propia, con datos de Migración Colombia, 2019 
Referente a la migración en los departamentos, se presenta como era de esperar, una mayor estancia de inmigrantes en las zonas fronterizas. Se destaca Nariño como el Departamento que en el 2018 tiene la mayor tasa de inmigrantes por cada 100.000 habitantes; pero a su vez, es uno de los que más salen migrantes, ya que, en dicho año, con fecha de corte de 1 de noviembre, se registró la salida de 511.001 venezolanos por el puente internacional de Rumichaca, Nariño (Migración Colombia, 2018). Lo anterior denota que los venezolanos que ingresan a esa zona del país lo hacen a manera de tránsito y no permanente, con el fin de trasladarse a otros países del continente, como Ecuador. Por otro lado, de los departamentos de la región Caribe, Guajira es el que mayor recepción de inmigrantes tiene, seguido del Departamento del Atlántico.

Tabla 1.

Inmigrantes venezolanos, desagregados por ocupación

\begin{tabular}{|c|c|c|c|c|c|}
\hline \multirow{2}{*}{ Ocupación } & \multicolumn{4}{|c|}{ Años } & \multirow{2}{*}{ Total } \\
\hline & 2015 & 2016 & 2017 & 2018 & \\
\hline Ama de casa & $\begin{array}{l}135.945 \\
26,73 \%\end{array}$ & $\begin{array}{l}69.557 \\
20,88 \%\end{array}$ & $\begin{array}{l}127.198 \\
18,44 \%\end{array}$ & $\begin{array}{l}199.400 \\
18,19 \%\end{array}$ & $\begin{array}{l}532.100 \\
20,25 \%\end{array}$ \\
\hline Comerciante & $\begin{array}{l}149.503 \\
29,40 \%\end{array}$ & $\begin{array}{l}102.051 \\
30,63 \%\end{array}$ & $\begin{array}{l}237.633 \\
34,46 \%\end{array}$ & $\begin{array}{l}407.993 \\
37,22 \%\end{array}$ & $\begin{array}{l}897.180 \\
34,15 \%\end{array}$ \\
\hline Sin especificar & $\begin{array}{l}62.480 \\
12,29 \%\end{array}$ & $\begin{array}{l}43.719 \\
13,12 \%\end{array}$ & $\begin{array}{l}85.661 \\
12,42 \%\end{array}$ & $\begin{array}{l}146.597 \\
13,37 \%\end{array}$ & $\begin{array}{l}338.457 \\
12,88 \%\end{array}$ \\
\hline Estudiante & $\begin{array}{l}53.937 \\
10,61 \%\end{array}$ & $\begin{array}{l}40.092 \\
12,03 \%\end{array}$ & $\begin{array}{l}105.104 \\
15,24 \%\end{array}$ & $\begin{array}{l}127.316 \\
11,62 \%\end{array}$ & $\begin{array}{l}326.449 \\
12,42 \%\end{array}$ \\
\hline Otros trabajadores & $\begin{array}{l}17.445 \\
3,43 \%\end{array}$ & $\begin{array}{l}21.626 \\
6,49 \%\end{array}$ & $\begin{array}{l}47.548 \\
6,89 \%\end{array}$ & $\begin{array}{l}109.588 \\
10,00 \%\end{array}$ & $\begin{array}{l}196.207 \\
7,47 \%\end{array}$ \\
\hline Ingeniero y afines & $\begin{array}{l}29.749 \\
5,85 \%\end{array}$ & $\begin{array}{l}22.475 \\
6,75 \%\end{array}$ & $\begin{array}{l}29.225 \\
4,24 \%\end{array}$ & $\begin{array}{l}31.234 \\
2,85 \%\end{array}$ & $\begin{array}{l}112.683 \\
4,29 \%\end{array}$ \\
\hline Profesor y/o Docente & $\begin{array}{l}20.952 \\
4,12 \%\end{array}$ & $\begin{array}{l}8.457 \\
2,54 \%\end{array}$ & $\begin{array}{l}15.899 \\
2,31 \%\end{array}$ & $\begin{array}{l}23.709 \\
2,16 \%\end{array}$ & $\begin{array}{l}69.017 \\
2,63 \%\end{array}$ \\
\hline Administrador y afines & $\begin{array}{l}14.372 \\
2,83 \%\end{array}$ & $\begin{array}{l}9.933 \\
2,98 \%\end{array}$ & $\begin{array}{l}17.160 \\
2,49 \%\end{array}$ & $\begin{array}{l}20.311 \\
1,85 \%\end{array}$ & $\begin{array}{l}61.776 \\
2,35 \%\end{array}$ \\
\hline Pensionado & $\begin{array}{l}12.561 \\
2,47 \%\end{array}$ & $\begin{array}{l}8.143 \\
2,44 \%\end{array}$ & $\begin{array}{l}11.907 \\
1,73 \%\end{array}$ & $\begin{array}{l}15.520 \\
1,42 \%\end{array}$ & $\begin{array}{l}48.131 \\
1,83 \%\end{array}$ \\
\hline Policia, militar o afines & $\begin{array}{l}11.612 \\
2,28 \%\end{array}$ & $\begin{array}{l}7.110 \\
2,13 \%\end{array}$ & $\begin{array}{l}12.354 \\
1,79 \%\end{array}$ & $\begin{array}{l}14.440 \\
1,32 \%\end{array}$ & $\begin{array}{l}45.516 \\
1,73 \%\end{array}$ \\
\hline Total & $\begin{array}{l}508.556 \\
100 \%\end{array}$ & $\begin{array}{l}333.163 \\
100 \%\end{array}$ & $\begin{array}{l}689.689 \\
100 \%\end{array}$ & $\begin{array}{l}1.096 .108 \\
100 \%\end{array}$ & $\begin{array}{l}2.627 .516 \\
100 \%\end{array}$ \\
\hline
\end{tabular}

Fuente: Elaboración propia, con datos de Migración Colombia, 2019

Considerando las ocupaciones que tienen los inmigrantes, se observa que, en el primer año, 2015, 23,09\% de los venezolanos que entran son comerciantes, 20,9\% son amas de casa, 9,65\% están sin especificar y el 8,3\% son estudiantes; los restantes ocupan profesiones como Ingenieros, profesores, administradores, entre otros. A priori, estas profesiones podrían considerarse como más susceptibles de conseguir un 
empleo informal, en vez de uno formal. Para los siguientes años se ve un incremento representativo en cuanto a los comerciantes, que pasan de representar el $23,09 \%$ de los inmigrantes del año 2015, a ser el 30,13\% en el año 2018. La segunda ocupación más representativa, las amas de casa, pasaron de ser el $20,9 \%$ en el 2015 , a ser solo el $14,7 \%$ en el 2018.

Tabla 2.

Mujeres inmigrantes venezolanas, desagregadas por ocupación

\begin{tabular}{lllllll}
\hline \multirow{2}{*}{ Ocupación } & \multicolumn{5}{c}{ Años } \\
\cline { 2 - 4 } & 2015 & 2016 & 2017 & 2018 & Total \\
\hline \multirow{2}{*}{ Ama de casa } & 131.587 & 67.131 & 124.119 & 192.906 & 515.743 \\
& $51,76 \%$ & $42,61 \%$ & $38,19 \%$ & $35,61 \%$ & $40,34 \%$ \\
Comerciante & 35.526 & 28.633 & 64.589 & 130.622 & 259.370 \\
& $13,97 \%$ & $18,17 \%$ & $19,88 \%$ & $24,11 \%$ & $20,29 \%$ \\
Sin especificar & 30.944 & 21.603 & 41.958 & 72.036 & 166.541 \\
& $12,17 \%$ & $13,71 \%$ & $12,91 \%$ & $13,30 \%$ & $13,03 \%$ \\
Estudiante & 28.616 & 20.429 & 53.083 & 68.437 & 170.565 \\
& $11,26 \%$ & $12,97 \%$ & $16,33 \%$ & $12,63 \%$ & $13,34 \%$ \\
Otros trabajadores & 7.144 & 8.983 & 20.411 & 48.729 & 85.267 \\
& $2,81 \%$ & $5,70 \%$ & $6,28 \%$ & $8,99 \%$ & $6,67 \%$ \\
Profesor y/o Docente & 12.795 & 5.445 & 10.769 & 16.503 & 45.512 \\
& $5,03 \%$ & $3,46 \%$ & $3,31 \%$ & $3,05 \%$ & $3,56 \%$ \\
Administrador y afines & 7.616 & 5.333 & 10.042 & 12.553 & 35.544 \\
& $3,00 \%$ & $3,38 \%$ & $3,09 \%$ & $2,32 \%$ & $2,78 \%$
\end{tabular}

Fuente: Elaboración propia, con datos de Migración Colombia, 2019

En las mujeres inmigrantes de Venezuela, la ocupación de ama de casa es la más representativa, con un 40,9\% del total de las inmigrantes, en el año 2015; para el año 2018 su representación disminuyó al 29,2\%. La segunda ocupación más representativa y que a su vez fue la que más creció, son las comerciantes, pasando de ser en el 2015 un $11,04 \%$ del total a ascender a la cifra de $19,8 \%$ en el 2018 . Otras ocupaciones a destacar son las estudiantes y profesoras, que pasaron de representar en el año 2015 el 8,8\% y $3,9 \%$, respectivamente, a ser en el año 2018 el 10,3\% y 2,5\%, respectivamente. 
Tabla 3.

Hombres inmigrantes venezolanos, desagregados por ocupación

\begin{tabular}{|c|c|c|c|c|c|}
\hline \multirow{2}{*}{ Ocupación } & \multicolumn{4}{|c|}{ Años } & \multirow{2}{*}{ Total } \\
\hline & 2015 & 2016 & 2017 & 2018 & \\
\hline Comerciante & $\begin{array}{l}113.977 \\
52,38 \%\end{array}$ & $\begin{array}{l}73.418 \\
46,41 \%\end{array}$ & $\begin{array}{l}173.044 \\
51,54 \%\end{array}$ & $\begin{array}{l}277.371 \\
53,41 \%\end{array}$ & $\begin{array}{l}637.810 \\
51,82 \%\end{array}$ \\
\hline Sin especificar & $\begin{array}{l}31.536 \\
14,49 \%\end{array}$ & $\begin{array}{l}22.116 \\
13,98 \%\end{array}$ & $\begin{array}{l}43.703 \\
13,02 \%\end{array}$ & $\begin{array}{l}74.561 \\
14,36 \%\end{array}$ & $\begin{array}{l}171.916 \\
13,97 \%\end{array}$ \\
\hline Estudiante & $\begin{array}{l}25.321 \\
11,64 \%\end{array}$ & $\begin{array}{l}19.663 \\
12,43 \%\end{array}$ & $\begin{array}{l}52.021 \\
15,49 \%\end{array}$ & $\begin{array}{l}58.879 \\
11,34 \%\end{array}$ & $\begin{array}{l}155.884 \\
12,67 \%\end{array}$ \\
\hline Otros trabajadores & $\begin{array}{l}10.301 \\
4,73 \%\end{array}$ & $\begin{array}{l}12.643 \\
7,99 \%\end{array}$ & $\begin{array}{l}27.137 \\
8,08 \%\end{array}$ & $\begin{array}{l}60.859 \\
11,72 \%\end{array}$ & $\begin{array}{l}110.940 \\
9,01 \%\end{array}$ \\
\hline Ingeniero y afines & $\begin{array}{l}22.472 \\
10,33 \%\end{array}$ & $\begin{array}{l}17.014 \\
10,76 \%\end{array}$ & $\begin{array}{l}20.992 \\
6,25 \%\end{array}$ & $\begin{array}{l}21.897 \\
4,22 \%\end{array}$ & $\begin{array}{l}82.375 \\
6,69 \%\end{array}$ \\
\hline Obrero y afines & $\begin{array}{l}5.197 \\
2,39 \%\end{array}$ & $\begin{array}{l}7.806 \\
4,93 \%\end{array}$ & $\begin{array}{l}11.059 \\
3,29 \%\end{array}$ & $\begin{array}{l}15.812 \\
3,04 \%\end{array}$ & $\begin{array}{l}39.874 \\
3,24 \%\end{array}$ \\
\hline Pensionado & $\begin{array}{l}8.804 \\
4,05 \%\end{array}$ & $\begin{array}{l}5.521 \\
3,49 \%\end{array}$ & $\begin{array}{l}7.772 \\
2,31 \%\end{array}$ & $\begin{array}{l}9.901 \\
1,91 \%\end{array}$ & $\begin{array}{l}31.998 \\
2,60 \%\end{array}$ \\
\hline Total & $\begin{array}{l}217.608 \\
100 \%\end{array}$ & $\begin{array}{l}158.181 \\
100 \%\end{array}$ & $\begin{array}{l}335.728 \\
100 \%\end{array}$ & $\begin{array}{l}519.280 \\
100 \%\end{array}$ & $\begin{array}{l}1.230 .797 \\
100 \%\end{array}$ \\
\hline
\end{tabular}

Fuente: Elaboración propia, con datos de Migración Colombia, 2019

Para el caso de los hombres, la ocupación más representativa es la de los comerciantes, pasando de ser en el 2015 el 34,9\% a ser en el 2018 el 39,9\%. En cambio, los pensionados, son de las condiciones que menos presentan los hombres inmigrantes venezolanos, al ser en el 2015 un 2,7\%, y con el paso del tiempo fueron disminuyendo gradualmente hasta llegar a un 1,4\% en el 2018. En el caso de los obreros se ve que en el 2015 del total de las entradas que se hicieron en ese año el 1,60\% son obreros y al 2018 no tuvo mucho impacto ya que del total de entradas de ese año solo el $2,28 \%$ son obreros y afines. 
Tabla 4.

Inmigrantes venezolanos, desagregados por nacionalidad

\begin{tabular}{|c|c|c|c|c|c|}
\hline \multirow{2}{*}{ País de origen } & \multicolumn{4}{|c|}{ Años } & \multirow{2}{*}{ Total } \\
\hline & 2015 & 2016 & 2017 & 2018 & \\
\hline Venezuela & $\begin{array}{l}244.128 \\
38,73 \%\end{array}$ & $\begin{array}{l}299.743 \\
71,19 \%\end{array}$ & $\begin{array}{l}672.580 \\
78,03 \%\end{array}$ & $\begin{array}{l}1.162 .155 \\
86,67 \%\end{array}$ & $\begin{array}{l}2.378 .606 \\
73,09 \%\end{array}$ \\
\hline Colombia & $\begin{array}{l}374.462 \\
59,41 \%\end{array}$ & $\begin{array}{l}113.370 \\
26,93 \%\end{array}$ & $\begin{array}{l}179.652 \\
20,84 \%\end{array}$ & $\begin{array}{l}167.603 \\
12,50 \%\end{array}$ & $\begin{array}{l}835.087 \\
25,66 \%\end{array}$ \\
\hline Ecuador & $\begin{array}{l}5.163 \\
0,82 \%\end{array}$ & $\begin{array}{l}3.017 \\
0,72 \%\end{array}$ & $\begin{array}{l}3.913 \\
0,45 \%\end{array}$ & $\begin{array}{l}4.661 \\
0,35 \%\end{array}$ & $\begin{array}{l}16.754 \\
0,51 \%\end{array}$ \\
\hline Perú & $\begin{array}{l}3.899 \\
0,62 \%\end{array}$ & $\begin{array}{l}2.733 \\
0,65 \%\end{array}$ & $\begin{array}{l}3.519 \\
0,41 \%\end{array}$ & $\begin{array}{l}4.083 \\
0,30 \%\end{array}$ & $\begin{array}{l}14.234 \\
0,44 \%\end{array}$ \\
\hline España & $\begin{array}{l}2.630 \\
0,42 \%\end{array}$ & $\begin{array}{l}2.158 \\
0,51 \%\end{array}$ & $\begin{array}{l}2.322 \\
0,27 \%\end{array}$ & $\begin{array}{l}2.424 \\
0,18 \%\end{array}$ & $\begin{array}{l}9.534 \\
0,29 \%\end{array}$ \\
\hline Total & $\begin{array}{l}630.282 \\
100 \%\end{array}$ & $\begin{array}{l}421.021 \\
100 \%\end{array}$ & $\begin{array}{l}861.986 \\
100 \%\end{array}$ & $\begin{array}{l}1.340 .926 \\
100 \%\end{array}$ & $\begin{array}{l}3.254 .215 \\
100 \%\end{array}$ \\
\hline
\end{tabular}

Fuente: Elaboración propia, con datos de Migración Colombia, 2019

Los inmigrantes de Venezuela con nacionalidad peruana se presentan muy poco en esta dinámica (Tabla 4), pues en el 2015 tuvieron solo un 0,60\% del total y al 2018 una disminución al registrar solo el 0,30 del total de ese año. En el caso de los ecuatorianos el total de las entradas representó solo el 0,8\% y al 2018 se muestra una disminución donde solo alcanzaron ser el 0,34 del total de ese año.

Si se considera la nacionalidad, la mayor inmigración corresponde a venezolanos y colombianos, que en el año 2015 representaron el 37,70\% y 57,83\% respectivamente; pero para el año 2018 la nacionalidad venezolana alcanza el 85,82\% del total de ese año. Se muestra una especie de primera oleada hacia Colombia, de colombianos que vivían en Venezuela y una segunda de venezolanos nacidos en aquel país. 
Tabla 5.

Entradas de venezolanos, desagregados por rangos de edad

\begin{tabular}{|c|c|c|c|c|c|}
\hline \multirow{2}{*}{ Rango de edad } & \multicolumn{4}{|c|}{ Años } & \multirow{2}{*}{ Total } \\
\hline & 2015 & 2016 & 2017 & 2018 & \\
\hline $0-17$ & $\begin{array}{l}62.673 \\
9,68 \%\end{array}$ & $\begin{array}{l}42.819 \\
9,80 \%\end{array}$ & $\begin{array}{l}84.310 \\
9,60 \%\end{array}$ & $\begin{array}{l}145.743 \\
10,76 \%\end{array}$ & $\begin{array}{l}335.545 \\
10,12 \%\end{array}$ \\
\hline $18-29$ & $\begin{array}{l}152.000 \\
23,47 \%\end{array}$ & $\begin{array}{l}125.956 \\
28,82 \%\end{array}$ & $\begin{array}{l}315.359 \\
35,92 \%\end{array}$ & $\begin{array}{l}454.135 \\
33,54 \%\end{array}$ & $\begin{array}{l}1.047 .450 \\
31,58 \%\end{array}$ \\
\hline $30-39$ & $\begin{array}{l}163.885 \\
25,31 \%\end{array}$ & $\begin{array}{l}106.808 \\
24,44 \%\end{array}$ & $\begin{array}{l}218.183 \\
24,85 \%\end{array}$ & $\begin{array}{l}355.945 \\
26,29 \%\end{array}$ & $\begin{array}{l}844.821 \\
25,47 \%\end{array}$ \\
\hline $40-49$ & $\begin{array}{l}119.816 \\
18,50 \%\end{array}$ & $\begin{array}{l}71.802 \\
16,43 \%\end{array}$ & $\begin{array}{l}125.390 \\
14,28 \%\end{array}$ & $\begin{array}{l}205.895 \\
15,21 \%\end{array}$ & $\begin{array}{l}522.903 \\
15,77 \%\end{array}$ \\
\hline $50-59$ & $\begin{array}{l}89.209 \\
13,78 \%\end{array}$ & $\begin{array}{l}50.960 \\
11,66 \%\end{array}$ & $\begin{array}{l}80.293 \\
9,15 \%\end{array}$ & $\begin{array}{l}118.813 \\
8,77 \%\end{array}$ & $\begin{array}{l}339.275 \\
10,23 \%\end{array}$ \\
\hline $60-69$ & $\begin{array}{l}44.903 \\
6,93 \%\end{array}$ & $\begin{array}{l}28.544 \\
6,53 \%\end{array}$ & $\begin{array}{l}40.900 \\
4,66 \%\end{array}$ & $\begin{array}{l}55.685 \\
4,11 \%\end{array}$ & $\begin{array}{l}170.032 \\
5,13 \%\end{array}$ \\
\hline 70 o más & $\begin{array}{l}15.086 \\
2,33 \%\end{array}$ & $\begin{array}{l}10.216 \\
2,34 \%\end{array}$ & $\begin{array}{l}13.479 \\
1,54 \%\end{array}$ & $\begin{array}{l}17.897 \\
1,32 \%\end{array}$ & $\begin{array}{l}56.678 \\
1,71 \%\end{array}$ \\
\hline Total & $\begin{array}{l}647.572 \\
100 \%\end{array}$ & $\begin{array}{l}437.105 \\
100 \%\end{array}$ & $\begin{array}{l}877.914 \\
100 \%\end{array}$ & $\begin{array}{l}1.354 .113 \\
100 \%\end{array}$ & $\begin{array}{l}3.316 .704 \\
100 \%\end{array}$ \\
\hline
\end{tabular}

Fuente: Elaboración propia, con datos de Migración Colombia, 2019

En el caso de los rangos de edad de los inmigrantes, se ve que los menores de edad en el 2015 tuvieron poco peso en el total de entradas, ya que solo fue el 9,68\%. En los mayores de 70 años entraron menos que las personas menores de 17 años representando el $2.33 \%$ del total de ese año; pero el rango de edad que más tuvo entrada en el año 2015 fueron los de 30-39 años ya que fue el 25,31\% del total de ese año, situación que seguramente va a impactar los indicadores laborales, tal como se analiza más adelante.

Al transcurrir los años se ve como han disminuido unos y otros han aumentado como en el rango de los mayores de 70 años se ve que en el año 2018 tuvo una disminución donde el 1,32\% del total de esas personas eran mayores de 70 años, pero el que sí tuvo un incremento significativo fueron las personas que van de los 18 a los 29 años donde el $33,9 \%$ de los entrantes venezolanos eran de ese rango de edad.

La informalidad no es más que el reflejo en el mercado de trabajo de la desigualdad, cuyos orígenes se encuentran en las características del crecimiento económico donde en periodos de crisis o recesión, esta puede ser como una válvula de escape para los individuos menos capacitados de la sociedad al no poder encontrar puestos de trabajo en el empleo formal (Ochoa Valencia \& Ordóñez, 2004; OIT, 2014). 
Gráfica 5: Tasa de informalidad por trimestre, 2015 - 2018

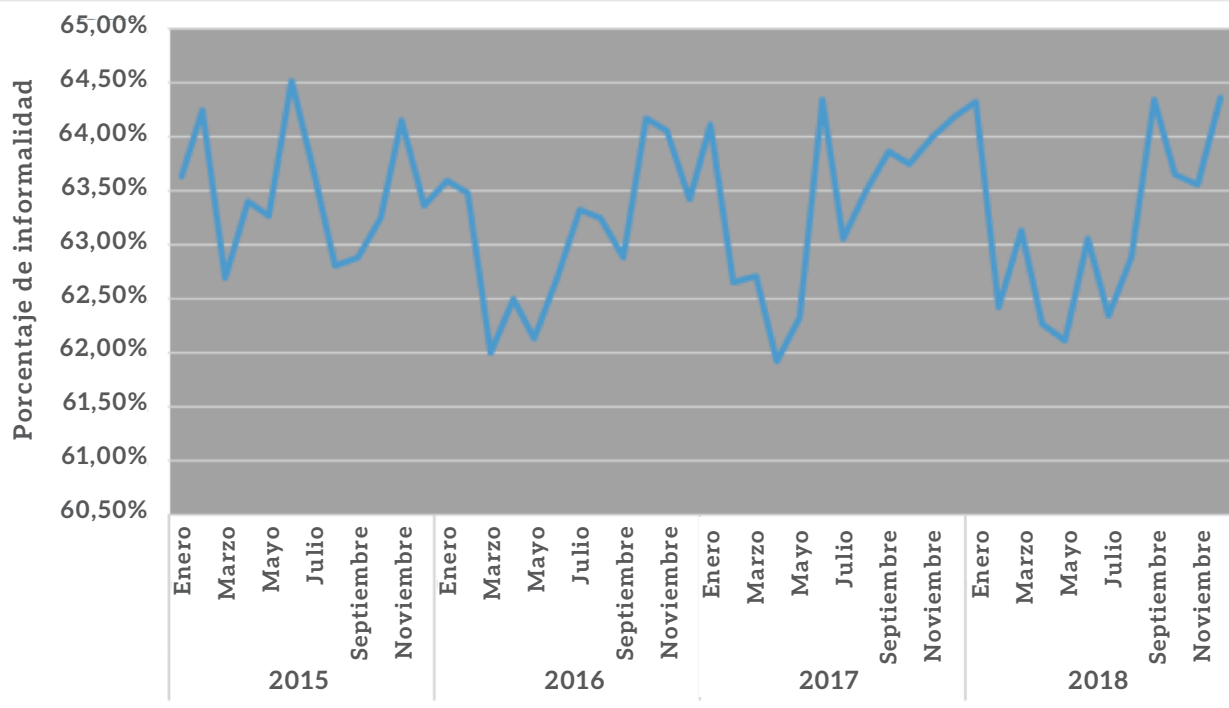

Fuente: Elaboración propia, con datos de la GEIH (DANE), 2019

A lo largo del periodo de estudio, la informalidad laboral oscila entre el $62 \%$ y el 64,5\%, el mayor pico que se ve en la tasa de informalidad se presenta en el 2015 en los meses de mayo a julio teniendo una tasa de informalidad de 64,5\%. Algo similar ocurre en el periodo de junio a julio de 2017 cuando la informalidad alcanzó un 64,25\%, la cual representa la segunda mayor informalidad que se da en los años estudiados.

Gráfica 6: Población informal y ocupados, por género y trimestre, 2015 - 2018

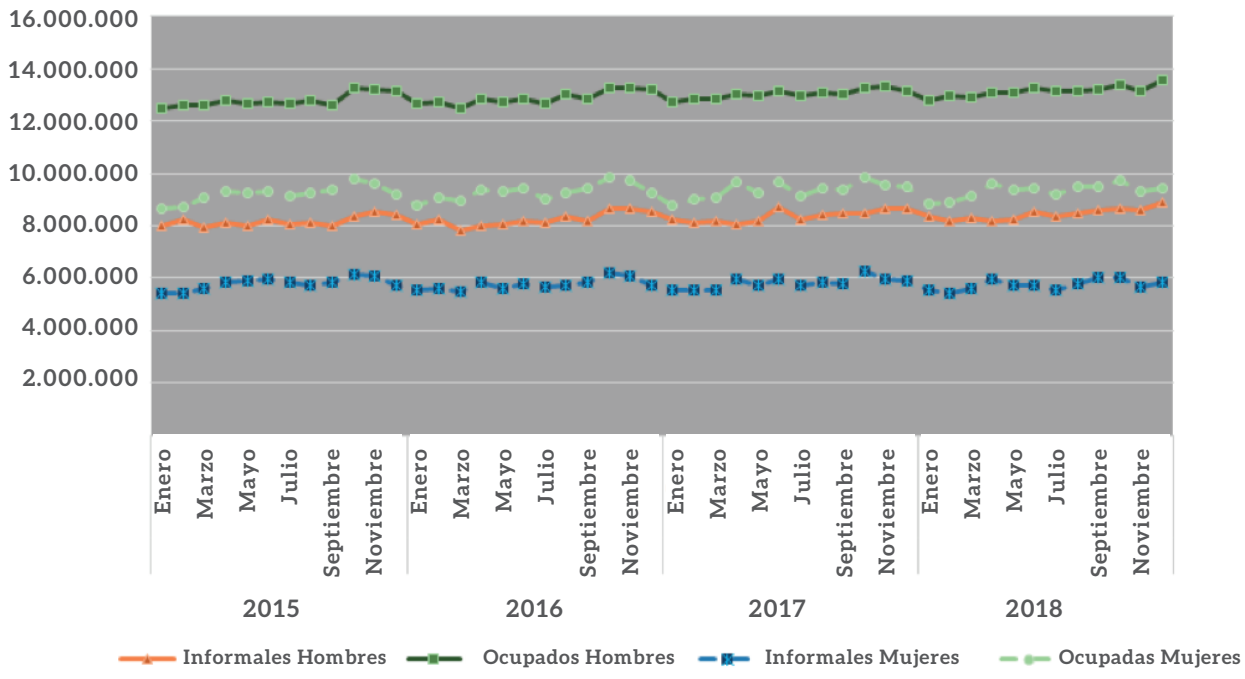

Fuente: Elaboración propia, con datos de la GEIH (DANE), 2019 
Al analizar el comportamiento de la cantidad de personas ocupadas y en informalidad, en los años 2015-2018, se nota que a nivel general sus comportamientos son relativamente constantes, donde el mayor afectado por la informalidad son los del género masculino, presentando una cifra de alrededor de 8,4 millones de personas en el último año. A su vez se observa que los hombres ocupan el mayor número de personas ocupadas sobrepasando de manera considerable a las mujeres por una cifra aproximada a los 4 millones.

Tabla 6.

Trabajadores en informalidad, por género

\begin{tabular}{|c|c|c|c|c|}
\hline \multirow{2}{*}{ Sexo } & \multicolumn{4}{|c|}{ Años } \\
\hline & 2015 & 2016 & 2017 & 2018 \\
\hline Hombre & $\begin{array}{l}8.174 .400 \\
58,48 \%\end{array}$ & $\begin{array}{l}8.229 .017 \\
58,83 \%\end{array}$ & $\begin{array}{l}8.365 .490 \\
58,97 \%\end{array}$ & $\begin{array}{l}8.453 .123 \\
59,55 \%\end{array}$ \\
\hline Mujer & $\begin{array}{l}5.804 .450 \\
41,52 \%\end{array}$ & $\begin{array}{l}5.759 .499 \\
41,17 \%\end{array}$ & $\begin{array}{l}5.820 .677 \\
41,03 \%\end{array}$ & $\begin{array}{l}5.742 .987 \\
40,45 \%\end{array}$ \\
\hline Total & $\begin{array}{l}13.978 .850 \\
100 \%\end{array}$ & $\begin{array}{l}13.988 .516 \\
100 \%\end{array}$ & $\begin{array}{l}14.186 .167 \\
100 \%\end{array}$ & $\begin{array}{l}14.196 .110 \\
100 \%\end{array}$ \\
\hline
\end{tabular}

Fuente: Elaboración propia, con datos de la GEIH (DANE), 2019

Respecto a los trabajadores que se encuentran en informalidad, desagregadas por género, se vislumbra que aquellos informales son mayormente hombres, y a su vez, a lo largo de los años estudiados estos han presentado un crecimiento. En el 2015, los trabajadores informales (hombres) representaba 8.174.400 los cuales representaban el 58,4\% del total y al término del 2018 alcanzaron una cantidad de 8.453.123 que representaban el 59,5\% del total de ese año.

En el caso de la informalidad laboral en las mujeres, se observa que a lo largo de los años estudiados estas presentan un decrecimiento, donde en el 2015 la cantidad de mujeres informales fue de 5.804.450 que representó el 41,5\% del total de ese año, mientras que en el 2018 estas eran 5.742.987 representando el 40,4\%. Lo anterior denota que, tanto en número como en proporción, algunas mujeres han pasado de ser trabajadoras informales a ser trabajadoras formales, en un escenario laboral, donde la cantidad de personas ocupadas ha venido en aumento. 
Tabla 7.

Trabajadores en informalidad, por estado civil

\begin{tabular}{|c|c|c|c|c|}
\hline \multirow{2}{*}{ Nivel de escolaridad } & \multicolumn{4}{|c|}{ Años } \\
\hline & 2015 & 2016 & 2017 & 2018 \\
\hline Unión libre con $<2$ años & $\begin{array}{l}410.484 \\
2,94 \%\end{array}$ & $\begin{array}{l}413.639 \\
2,96 \%\end{array}$ & $\begin{array}{l}459.006 \\
3,24 \%\end{array}$ & $\begin{array}{l}460.093 \\
3,24 \%\end{array}$ \\
\hline Unión libre con 2 años & $\begin{array}{l}4.527 .726 \\
32,39 \%\end{array}$ & $\begin{array}{l}4.603 .354 \\
32,91 \%\end{array}$ & $\begin{array}{l}4.735 .321 \\
33,38 \%\end{array}$ & $\begin{array}{l}4.887 .895 \\
34,43 \%\end{array}$ \\
\hline Casado (a) & $\begin{array}{l}3.143 .634 \\
22,49 \%\end{array}$ & $\begin{array}{l}3.161 .621 \\
22,60 \%\end{array}$ & $\begin{array}{l}3.075 .146 \\
21,68 \%\end{array}$ & $\begin{array}{l}3.007 .434 \\
21,18 \%\end{array}$ \\
\hline Separado (a) & $\begin{array}{l}2.062 .335 \\
14,75 \%\end{array}$ & $\begin{array}{l}2.099 .158 \\
15,01 \%\end{array}$ & $\begin{array}{l}2.128 .720 \\
15,01 \%\end{array}$ & $\begin{array}{l}2.167 .594 \\
15,27 \%\end{array}$ \\
\hline Viudo (a) & $\begin{array}{l}477.640 \\
3,42 \%\end{array}$ & $\begin{array}{l}461.136 \\
3,30 \%\end{array}$ & $\begin{array}{l}469.952 \\
3,31 \%\end{array}$ & $\begin{array}{l}431.419 \\
3,04 \%\end{array}$ \\
\hline Soltero (a) & $\begin{array}{l}3.357 .031 \\
24,02 \%\end{array}$ & $\begin{array}{l}3.249 .608 \\
23,23 \%\end{array}$ & $\begin{array}{l}3.318 .022 \\
23,39 \%\end{array}$ & $\begin{array}{l}3.241 .675 \\
22,83 \%\end{array}$ \\
\hline Total & $\begin{array}{l}13.978 .850 \\
100 \%\end{array}$ & $\begin{array}{l}13.988 .516 \\
100 \%\end{array}$ & $\begin{array}{l}14.186 .167 \\
100 \%\end{array}$ & $\begin{array}{l}14.196 .110 \\
100 \%\end{array}$ \\
\hline
\end{tabular}

Fuente: Elaboración propia, con datos de la GEIH (DANE), 2019

Al hablar del estado civil de las personas en informalidad, se observa que para el 2015 la mayor proporción de estas viven en unión libre desde hace 2 o más años representando el $32,3 \%$; luego le siguen los que son solteros, con un $24 \%$, los casados con un $22,4 \%$ y las personas separadas con un $14,7 \%$.

Las personas en unión libre desde hace 2 años o más presentan un crecimiento, donde en el año 2018 aumentaron en su proporción 2,1 puntos porcentuales, y las personas separadas también presentan un crecimiento, pero de manera más leve, de 0,5 puntos porcentuales. Con respecto a los solteros y casados, se observa una disminución en ambos a lo largo de los años de estudio, en el cual sus proporciones bajaron a 22,8\% y $21,1 \%$, respectivamente. 
Tabla 8.

Trabajadores en informalidad, por nivel educativo

\begin{tabular}{|c|c|c|c|c|}
\hline \multirow{2}{*}{ Nivel de escolaridad } & \multicolumn{4}{|c|}{ Años } \\
\hline & 2015 & 2016 & 2017 & 2018 \\
\hline Ninguno & $\begin{array}{l}879.675 \\
6,29 \%\end{array}$ & $\begin{array}{l}874.578 \\
6,25 \%\end{array}$ & $\begin{array}{l}862.244 \\
6,08 \%\end{array}$ & $\begin{array}{l}827.860 \\
5,83 \%\end{array}$ \\
\hline Preescolar & $\begin{array}{l}1.816 \\
0,01 \%\end{array}$ & $\begin{array}{l}1.122 \\
0,01 \%\end{array}$ & $\begin{array}{l}1.199 \\
0,01 \%\end{array}$ & $\begin{array}{l}916 \\
0,01 \%\end{array}$ \\
\hline Básica primaria & $\begin{array}{l}4.937 .452 \\
35,32 \%\end{array}$ & $\begin{array}{l}4.793 .224 \\
34,27 \%\end{array}$ & $\begin{array}{l}4.792 .635 \\
33,78 \%\end{array}$ & $\begin{array}{l}4.608 .373 \\
32,46 \%\end{array}$ \\
\hline Básica secundaria & $\begin{array}{l}2.679 .948 \\
19,17 \%\end{array}$ & $\begin{array}{l}2.654 .836 \\
18,98 \%\end{array}$ & $\begin{array}{l}2.613 .943 \\
18,43 \%\end{array}$ & $\begin{array}{l}2.601 .899 \\
18,33 \%\end{array}$ \\
\hline Media & $\begin{array}{l}3.541 .387 \\
25,33 \%\end{array}$ & $\begin{array}{l}3.680 .308 \\
26,31 \%\end{array}$ & $\begin{array}{l}3.862 .002 \\
27,22 \%\end{array}$ & $\begin{array}{l}4.046 .769 \\
28,51 \%\end{array}$ \\
\hline Superior o universitaria & $\begin{array}{l}1.933 .154 \\
13,83 \%\end{array}$ & $\begin{array}{l}1.980 .170 \\
14,16 \%\end{array}$ & $\begin{array}{l}2.051 .414 \\
14,46 \%\end{array}$ & $\begin{array}{l}2.107 .901 \\
14,85 \%\end{array}$ \\
\hline No sabe, no informa & $\begin{array}{l}5.418 \\
0,04 \%\end{array}$ & $\begin{array}{l}4.278 \\
0,03 \%\end{array}$ & $\begin{array}{l}2.730 \\
0,02 \%\end{array}$ & $\begin{array}{l}2.392 \\
0,02 \%\end{array}$ \\
\hline Total & $\begin{array}{l}13.978 .850 \\
100 \%\end{array}$ & $\begin{array}{l}13.988 .516 \\
100 \%\end{array}$ & $\begin{array}{l}14.186 .167 \\
100 \%\end{array}$ & $\begin{array}{l}14.196 .110 \\
100 \%\end{array}$ \\
\hline
\end{tabular}

Fuente: Elaboración propia, con datos de la GEIH (DANE), 2019

Está aceptado que la educación es un factor determinante del mejoramiento de las condiciones en que las personas participan en el mercado laboral, donde se entiende informalidad como una condición laboral marcada por la precariedad del empleo. En efecto se puede mirar que las personas con mayor informalidad son las que tienen un bajo nivel educativo de básica primaria, y que en el año 2015 representaron un 35,32\% del total de los encuestados en dicho año, condición que se mantiene a lo largo de estos años, obteniendo un 32,46\% del total en el año 2018. El siguiente que tiene un impacto significativo en la informalidad son las personas que solo terminaron hasta un nivel educativo medio $\left(10^{\circ}-11^{\circ}\right)$, representando el 25,33\% del total del año 2015 situándose así en el segundo nivel educativo con más impacto y teniendo un crecimiento en los años estudiados, llegando al 28,51\% del total en el año 2018. Como tercer mayor grupo poblacional por nivel de educación en estado de informalidad, son las personas que tienen una básica secundaria $\left(6^{\circ}-9^{\circ}\right)$ el cual en el primer año de estudio significa un 19,17\% y para el 2018 un poco, situándose en 18,33\% del total de ese año, pero manteniéndose en la tercera más significante. 
Tabla 8.

Trabajadores en informalidad, por nivel educativo

\begin{tabular}{|c|c|c|c|c|}
\hline \multirow{2}{*}{ Nivel de escolaridad } & \multicolumn{4}{|c|}{ Años } \\
\hline & 2015 & 2016 & 2017 & 2018 \\
\hline Ninguno & $\begin{array}{l}879.675 \\
6,29 \%\end{array}$ & $\begin{array}{l}874.578 \\
6,25 \%\end{array}$ & $\begin{array}{l}862.244 \\
6,08 \%\end{array}$ & $\begin{array}{l}827.860 \\
5,83 \%\end{array}$ \\
\hline Preescolar & $\begin{array}{l}1.816 \\
0,01 \%\end{array}$ & $\begin{array}{l}1.122 \\
0,01 \%\end{array}$ & $\begin{array}{l}1.199 \\
0,01 \%\end{array}$ & $\begin{array}{l}916 \\
0,01 \%\end{array}$ \\
\hline Básica primaria & $\begin{array}{l}4.937 .452 \\
35,32 \%\end{array}$ & $\begin{array}{l}4.793 .224 \\
34,27 \%\end{array}$ & $\begin{array}{l}4.792 .635 \\
33,78 \%\end{array}$ & $\begin{array}{l}4.608 .373 \\
32,46 \%\end{array}$ \\
\hline Básica secundaria & $\begin{array}{l}2.679 .948 \\
19,17 \%\end{array}$ & $\begin{array}{l}2.654 .836 \\
18,98 \%\end{array}$ & $\begin{array}{l}2.613 .943 \\
18,43 \%\end{array}$ & $\begin{array}{l}2.601 .899 \\
18,33 \%\end{array}$ \\
\hline Media & $\begin{array}{l}3.541 .387 \\
25,33 \%\end{array}$ & $\begin{array}{l}3.680 .308 \\
26,31 \%\end{array}$ & $\begin{array}{l}3.862 .002 \\
27,22 \%\end{array}$ & $\begin{array}{l}4.046 .769 \\
28,51 \%\end{array}$ \\
\hline Superior o universitaria & $\begin{array}{l}1.933 .154 \\
13,83 \%\end{array}$ & $\begin{array}{l}1.980 .170 \\
14,16 \%\end{array}$ & $\begin{array}{l}2.051 .414 \\
14,46 \%\end{array}$ & $\begin{array}{l}2.107 .901 \\
14,85 \%\end{array}$ \\
\hline No sabe, no informa & $\begin{array}{l}5.418 \\
0,04 \%\end{array}$ & $\begin{array}{l}4.278 \\
0,03 \%\end{array}$ & $\begin{array}{l}2.730 \\
0,02 \%\end{array}$ & $\begin{array}{l}2.392 \\
0,02 \%\end{array}$ \\
\hline Total & $\begin{array}{l}13.978 .850 \\
100 \%\end{array}$ & $\begin{array}{l}13.988 .516 \\
100 \%\end{array}$ & $\begin{array}{l}14.186 .167 \\
100 \%\end{array}$ & $\begin{array}{l}14.196 .110 \\
100 \%\end{array}$ \\
\hline
\end{tabular}

Fuente: Elaboración propia, con datos de la GEIH (DANE), 2019

Con respecto a la informalidad por rango etario, se encontró que las personas mayores de 40 años representan la mayor informalidad a lo largo de los años estudiados, donde en el 2015 representó un 49,11\% del total de personas en informalidad llegando a registrar en el 2018 el 49,76\% del total. Para las personas con el rango de 25 a 40 años en el 2015 ellos representaron el 32,83\% de los encuestados en dicho año y creció para el 2018 a un 33,71\%. Como último rango por edad, según grado de informalidad, están los menores de 25 años, representando solo el 18,06\% del total en el 2015 y disminuyendo a lo largo de los años estudiados llegando a ser solo el 16,53\% del total del año 2018.

A continuación (Tabla 10) se presenta la estimación logística propuesta para analizar los efectos de la inmigración venezolana en el mercado laboral colombiano: 
Tabla 10.

Estimación del modelo logístico (LOGIT)

\begin{tabular}{lll}
\hline \multicolumn{2}{c}{ Variable } & Coeficiente \\
\hline Sexo Mujer & $0,1942^{* * *}$ \\
& $(0,0044)$ & $-0,1862^{* * *}$ \\
Grupo de edad $25-40$ & $(0,0062)$ \\
& Más de 40 & $0,309^{* * *}$ \\
& $(0,0065)$ \\
& Jefe de hogar & $-0,155^{* * *}$ \\
& $(0,0047)$ \\
Años de escolaridad & $-0,229^{* * *}$ \\
& $(0,0006)$ \\
Inmigrantes & $2,52 \mathrm{E}-06^{* * *}$ \\
Venezolanos & $(7,30 \mathrm{E}-07)$ \\
\hline N & $1,139,052$ \\
Pseudo $\mathbf{R}^{2}$ & $16,32 \%$
\end{tabular}

Nota: ${ }^{*} \mathrm{P}<0.1,{ }^{* *} \mathrm{P}<0.05,{ }^{* * *} \mathrm{P}<0.0$. Los erros estándar entre paréntesis.

Fuente: Elaboración propia, con datos de la GEIH (DANE) y Migración Colombia, 2019

Posteriormente, se presentan los efectos marginales de la estimación, para de esta manera poder aislar los efectos individuales que tiene cada variable independiente sobre la condición de Informalidad (Tabla 11).

Tabla 11.

Efectos marginales

\begin{tabular}{|c|c|c|c|c|c|c|c|}
\hline \multirow{2}{*}{\multicolumn{2}{|c|}{ Variable }} & \multicolumn{2}{|c|}{ Delta-method } & \multirow{2}{*}{$\mathrm{Z}$} & \multirow{2}{*}{$\mathrm{P}>|\mathrm{z}|$} & \multirow{2}{*}{\multicolumn{2}{|c|}{ [95\% conf. Interval] }} \\
\hline & & $\mathrm{dy} / \mathrm{dx}$ & Std. Err & & & & \\
\hline Sexo & Mujer & 0,037 & 8,51E-05 & 44,2 & 0,000 & 0,036 & 0,039 \\
\hline \multirow[t]{5}{*}{ Grupo de edad } & $25-40$ & $-0,037$ & 0,0012 & $-30,11$ & 0,000 & $-0,0397$ & $-0,0348$ \\
\hline & Más de 40 & 0,06 & 0,0013 & 46,81 & 0,000 & 0,0578 & 0,0628 \\
\hline & Jefe de hogar & $-0,03$ & 0,00091 & $-33,1$ & 0,000 & $-0,0318$ & $-0,0282$ \\
\hline & $\begin{array}{l}\text { Años de } \\
\text { escolaridad }\end{array}$ & $-0,044$ & 0,00009 & $-510,83$ & 0,000 & $-0,0446$ & $-0,0443$ \\
\hline & $\begin{array}{l}\text { Inmigrantes } \\
\text { Venezolanos }\end{array}$ & $4,90 \mathrm{E}-07$ & $1,42 \mathrm{E}-07$ & 3,46 & 0,001 & $2,12 \mathrm{E}-07$ & $7,68 \mathrm{E}-07$ \\
\hline
\end{tabular}

Fuente: Elaboración propia, con datos de la GEIH (DANE) y Migración Colombia, 2019 
Con respecto al género, se obtuvo que ser mujer aumenta la probabilidad de ser informal, 3,7\% en relación al género masculino. Este resultado puede explicarse porque por lo general las mujeres ofrecen su fuerza de trabajo más por obtener un salario complementario, ya que también tienen obligaciones en el hogar, por tanto, les es perentorio conseguir empleos más flexibles (Ochoa Valencia \& Ordóñez, 2004).

En cuanto a la edad, la probabilidad de ser informal para las personas con edades intermedias de entre 25 y 40 años, son menores a las de las personas menores de 25 años en un 3,7\%; mientras que la probabilidad de ser informal para las personas el rango de edad de mayores de 40 años es superior a las de las personas menores de 25 años en un 6,03\%. Este resultado sugiere que en las edades donde las personas son menos productivas (menos de 25 años y superior a los 40 años), estas son menos propensas a encontrar empleo en el sector formal, y por lo tanto les toca entrar al sector informal, lo cual es congruente con la evidencia internacional (Ochoa Valencia \& Ordóñez, 2004).

\section{CONCLUSIONES}

La evidencia señala que, para el caso de los jefes de hogar, la probabilidad de encontrarse empleado en el mercado laboral informal es en promedio 3\%, y menor si se compara con los demás integrantes del hogar. Por otra parte, la escolaridad de los individuos está correlacionada significativamente con el grado de formalidad del empleo. En promedio, un año más de formación académica disminuye la probabilidad de ser informal en cerca de 4,4 puntos porcentuales.

Por último, se comprobó que la inmigración de ciudadanos venezolanos ha incidido en el mercado laboral colombiano: por cada inmigrante que ingresa a una ciudad en Colombia, la probabilidad de que un trabajador sea informal en esa ciudad, aumenta en un 0,000049, es decir, si en esa ciudad ingresan 10.000 venezolanos, la probabilidad que tiene un individuo de ser informal es del 0,49\%.

\section{REFERENCIAS BIBLIOGRAFICAS}

Aguado Mazuera, Á. H. (2018). La empleabilidad de migrantes Venezolanos en el mercado laboral Cali. Cali, Colombia: Pontificia Universidad Javeriana de Cali.

Aruj, R. (2008). Causas, consecuencias, efectos e impacto de las migraciones en Latinoamérica. Papeles de población, 95-116.

Becerra Elejalde, L. L. (2019). Venezolanos con pasaporte vencido podrán ingresar al país por un periodo de dos años. La República.

Contreras Guajardo, D., Ruiz-Tagle Venero, J., \& Sepúlveda, P. (2013). Migración y Mercado Laboral en Chile. Santiago, chile: Universidad de Chile.

Gaceta oficial. (2017). Gaceta Oficial de la República Bolivarana de Venezuela. Caracas.

Gámez, A., Wilson, T. D., \& Boncheva, A. I. (2010). Las mujeres en la migración interna y el empleo informal en Baja California Sur, México. Revista de estudios de género, 214-243. 
Marx, K. (1867). Das Kapital. Washington: Gateway .

Migración Colombia. (2016). Migración: Ministerio de Relaciones Exteriores. Obtenido de http://www.migracioncolombia.gov.co/index.php/es/ prensa/comunicados/comunicados-2016/agosto-2016/apertura-defrontera/3221-director-de-migracion-colombia-aclara-dudas-sobre-latarjeta-migratoria-de-transito-fronterizo

Migración Colombia. (2018). Colombia y Venezuela: Más que 2.200 kilómetros de fronteras. Bogotá, Colombia: Migración Colombia.

Moreno Losada, V. (10 de Diciembre de 2017). Denuncias por numerosos votos asistidos. Obtenido de Efecto Cocuyo: http://efectococuyo.com/politica/ denuncias-por-numerosos-votos-asistidos-son-las-mas-comunes-este10dic-segun-rondon/

OCHA. (2019). COLOMBIA: Desplazamientos masivos en Puerto Libertador (Córdoba) Reporte de Situación No. 01. New York: Oficina de Naciones Unidas para la Coordinación de Asuntos Humanitarios.

Ochoa Valencia, D., \& Ordóñez, A. (2004). Informalidad en Colombia: Causas, efectos y características de la economía del rebusque. Estudios Gerenciales, 103-116.

Ricardo, D. (2003). Principios de economía política y tributación. Madrid, España: Piramide.

Scharfenberg, E. (2016). Maduro ordena el cierre de la frontera con Colombia durante 72 horas. Obtenido de El Pais: https://elpais.com/internacional/ 2016/12/13/colombia/1481586930_332948.html

Uribe, J. I. (2006). Informalidad laboral en Colombia 1988-2000. Evolución, teorías y modelos. Cali, Colombia: Universidad del Valle.

Valenzuela, P., Riveros, K., Palomo, N., Araya, I., Campos, B., Salazar, C., \& Tavie, C. (2018). Integración laboral de los inmigrantes haitianos, dominicanos y colombianos en Santiago de Chile. Santiago, Chile: Dirección de Investigaciones y Estudios de la Universidad Academia de Humanismo Cristiano. 